\title{
Acute Cholecystitis of a Duplicated Gallbladder with Double Cystic Duct in a 10 Year Old Boy
}

\author{
Süreyya Burcu Görkem ${ }^{1}$, Selim Doğanay ${ }^{1}$, Güven Kahriman², Mustafa Küçükaydın³ , Abdülhakim Coşkun ${ }^{1}$
}

\begin{abstract}
${ }^{1}$ Department of Radiology, Pediatric Radiology Section, Erciyes University Faculty of Medicine, Kayseri, Turkey ${ }^{2}$ Department of Radiology, Interventional Radiology Section, Erciyes University Faculty of Medicine, Kayseri, Turkey ${ }^{3}$ Department of Pediatric Surgery, Erciyes University Faculty of Medicine, Kayseri, Turkey
\end{abstract}

A 10 year-old boy was referred to the children's emergency service with complaints of jaundice, vomiting, fever and right upper quadrant abdominal pain. He had Murphy’s sign during his physical examination, and a history of thalassemia minor. Laboratory data revealed acute cholecystitis with significant elevations of cholestatic liver enzymes. An abdominal ultrasound (US) (ACUSON Antares Siemens Medical Systems, Erlangen, Germany) showed two hydropic gallbladders which had thickened echogenic separated walls containing millimetric gallstones and sludge formation with two cystic ducts en-

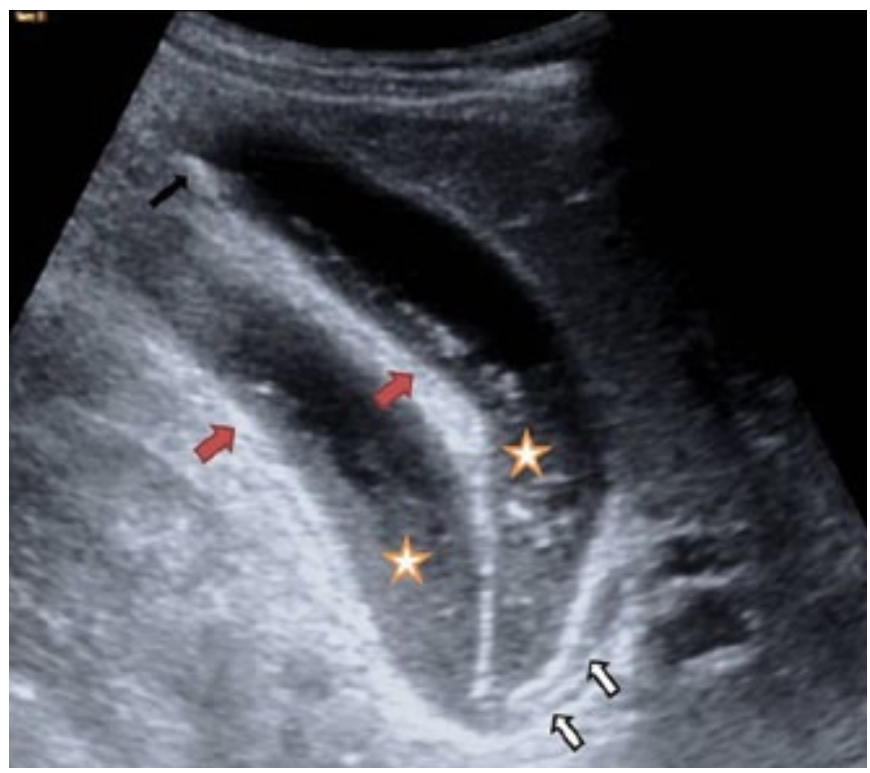

FIG. 1. Double gallbladders with double cystic ducts (white arrows) with inflamed walls (red arrows), sludge formation (stars) and stone (small black arrow) are shown on coronal ultrasound image tering the common bile duct (Figure 1). The common hepatic duct and common bile duct were enlarged. Magnetic resonance cholangiopancreatography (MRCP) (AERA 1.5T Siemens Medical Systems, Erlangen, Germany) showed a normal liver with two gallbladders with wall inflammations, two cystic ducts and dilated common bile and hepatic duct due to gallstones (Figure 2, 3). The patient underwent a percutanous transhepatic cholangiography (PTC) for the management of obstructive cholestasis (Figure 4). The gallstones in the common bile duct were successfully removed into the duodenum. Biliary drainage was maintained. After the laparoscopic cholecystectomy, the patient recovered.

Gallbladder duplication is an uncommon anomaly of the biliary tree in the paediatric population. Duplicated gallbladders

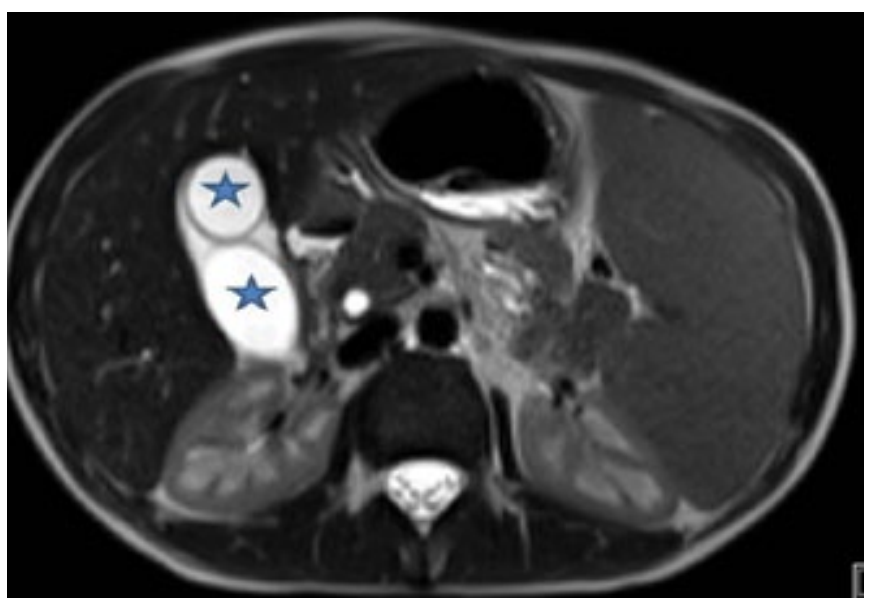

FIG. 2. Axial T2 HASTE image of MRCP shows two hydropic gallbladders with separated-inflamed walls (stars)

This case was presented as an e-poster at the 35th Matiional Radiology Congress, 11-15 November 2014, Antalya, Turkey.

Address for Correspondence: Dr. Süreyya Burcu Görkem, Department of Radiology, Pediatric Radiology Section, Erciyes University Faculty of Medicine, Kayseri, Turkey Phone: +903524374901 e-mail: drburcugorkem@gmail.com

Received: 05.05.2014 Accepted: 09.10.2014 • DOI: 10.5152/balkanmedj.2014.14381

Available at www.balkanmedicaljournal.org

Görkem SB, Doğanay S, Kahriman G, Küçükaydın M, Coșkun A. Acute cholecystitis of a duplicated gallbladder with double cystic duct in a 10 year old boy. Balkan Med J 2014;31:366-7. 


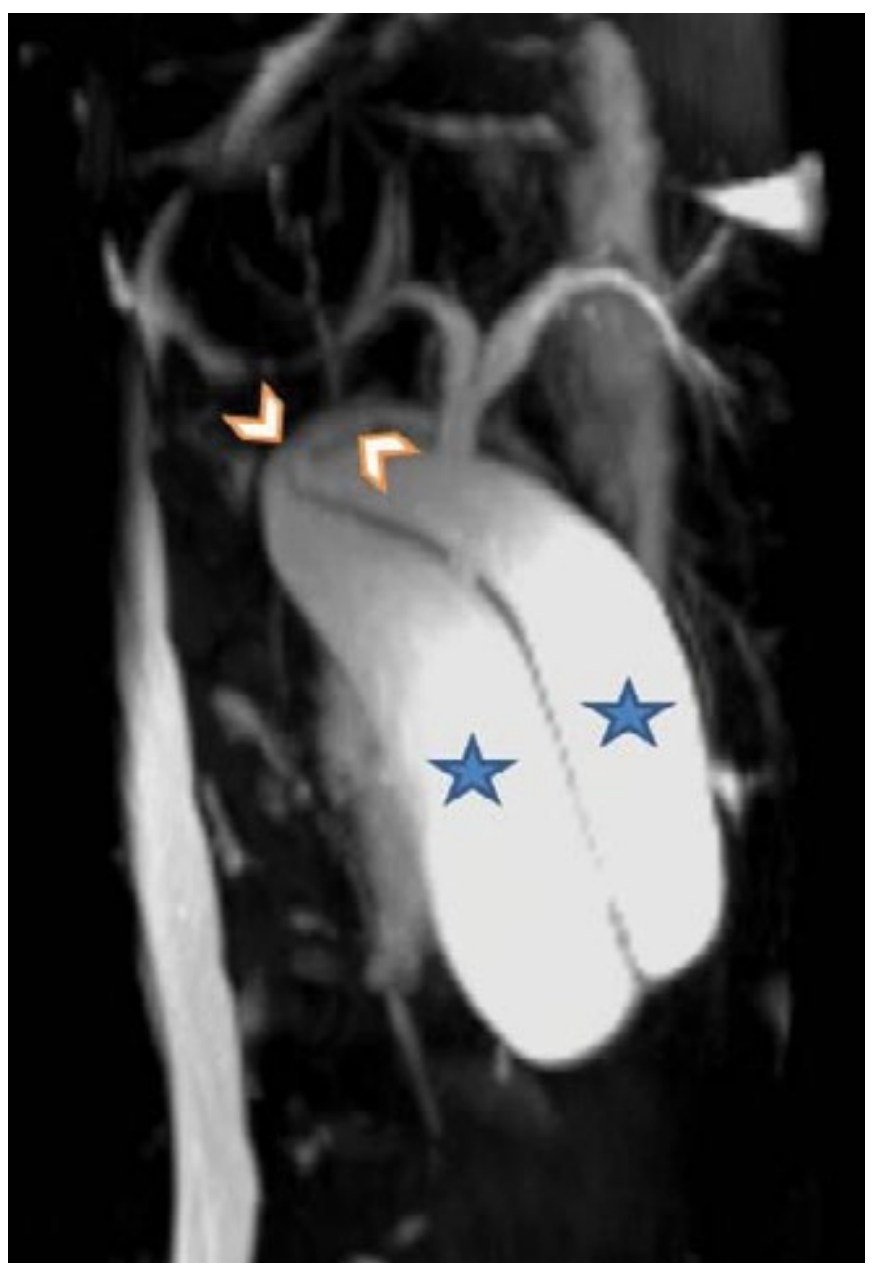

FIG. 3. 3D Coronal MIP image of MRCP demonstrates duplication of gallbladder (stars) with two cystic ducts (arrow heads)

are classified into subgroups based on the anatomy of the gallbladder and biliary ducts. "Ductular" type, in which cystic ducts are separately joined to the common bile duct, is the commonest variant of the gallbladder (1). Acute or chronic cholecystitis is observed due to stone or sludge formation; also, fistulas, torsion, papilloma or carcinoma may occur (2). US is the first line imaging technique for diagnosing the duplication anomalies (2). MRCP is a non-invasive imaging modality without X-ray exposure which can give an accurate diagnosis of duplication anomaly both in adults and children (3-5). PTC is a therapeutic invasive technique where stones or sludge formation can be removed to the duodenum or extracted in order to maintain biliary drainage in the same session (5). Surgical resection of duplicated gallbladders should be considered in symptomatic and complicated patients. In conclusion, a multimodality approach including PTC should also be considered to establish the diagnosis preoperatively and to maintain biliary drainage in obstructive cholestasis in children.

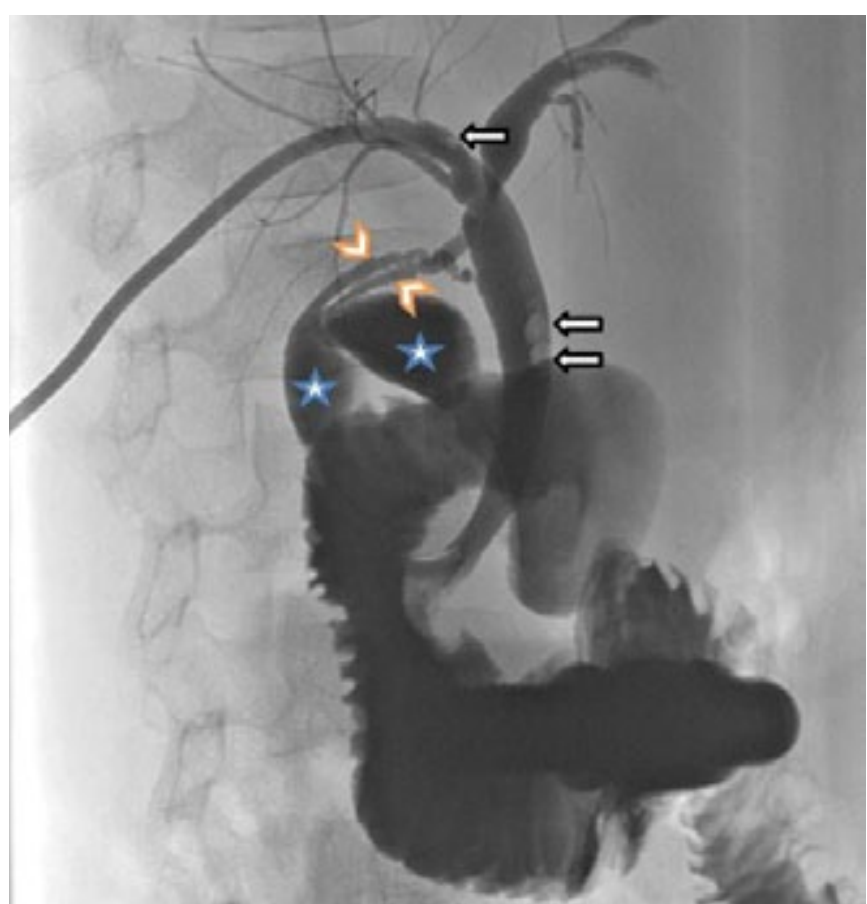

FIG. 4. Stones (white arrows) in enlarged common hepatic and common bile duct are demonstrated on PTC. Duplication of gallbladders (stars) with double cystic ducts (arrow heads) are shown

\section{Ethics Committee Approval: N/A.}

Informed Consent: Written informed consent was obtained from the patient's parents for the publication of this case and any accompanying images.

Peer-review: Externally peer-reviewed.

Author contributions: Concept - S.B.G.; Design - S.B.G., S.D.; Supervision - A.C.; Resource - S.B.G., S.D., G.K., M.K.; Materials - S.B.G., S.D., G.K., M.K.; Data Collection\&/or Processing - S.B.G., S.D., G.K., M.K.; Analysis\&/or Interpretation S.B.G., S.D., G.K., M.K.; Literature Search S.B.G.; Writing S.B.G.; Critical Reviews - A.C.

Conflict of Interest: No conflict of interest was declared by the authors.

Financial Disclosure: The authors declared that this study has received no financial support.

\section{REFERENCES}

1. Boyden EA The accessory gallbladder: an embryological and comparative study of aberrant biliary vesicles occurring in man and the domestic mammals. Am J Anat 1926;38:177-231.[CrossRef]

2. Causey MW, Miller S, Fernelius CA, Burgess JR, Brown TA, Newton C. Gallbladder duplication: Evaluation, treatment, and classification. $J$ Pediatr Surg 2010;45:443-6.[CrossRef]

3. Gerscovich EO, Towner D, Sanchez T, Stein-Wexler R, Rhee-Morris L. Fetal gallbladder duplication J Ultrasound Med 2011;30:1310-2.

4. Menon P, Rao KL, Thapa BR, Goyal R, Garge S, Rathore MK, et al. Duplicated gall bladder with duodenal duplication cyst. J Pediatr Surg 2013;48:25-8. [CrossRef]

5. Ouida F, Taieb C, Hela L, et al. Duplication of gallbladder. Tunis Med 2011;89:798-9. 